\title{
NEAPELJSKA VILANELA V KOMIČNI KULTURI AVSTRIJSKIH DEŽEL OK. LETA 1570: PRIMER NAPOLITAN GIACOMA GORZANISA
}

\author{
ALENKA BAGARIČ \\ Narodna in univerzitetna knjižnica, Ljubljana
}

\begin{abstract}
Izvleček: Neapeljske vilanele Giacoma Gorzanisa so preproste ljubezenske pesmice, polne duhovitih, zbadljivih in posmehljivih prispodob. Karikirano podajanje besedil privzame izrazito komičen značaj in ponuja številne priložnosti za vključevanje mimičnih in gestikularnih elementov. Motrenje s tega vidika razkriva širitev vilanele $v$ dežele onstran italijanskega govornega področja.
\end{abstract}

Ključne besede: neapeljska vilanela, napolitana, Giacomo Gorzanis, italijanska komična kultura

\begin{abstract}
Villanelle alla napolitana by Giacomo Gorzanis are simple love songs, full of wit, taunting and mocking. The caricature presentation of the lyrics has a recognizable comic effect, and provides opportunities for improvised mimic and gesticulatory elements. These characteristics occur as the essential elements of the dissemination of genre to countries beyond the Italian speaking area.
\end{abstract}

Keywords: villanella alla napolitana, napolitana, Giacomo Gorzanis, Italian comic culture

Za naslovnima oznakama "villanella alla napolitana« in »napolitana« (v sodobni strokovni literaturi zaobjetima z generičnima izrazoma neapeljska vilanela oz. vilanela) ${ }^{1}$ so se v italijanskih glasbenih tiskih ok. leta 1570 skrivale zabavne ljubezenske pesmi, katerih besedilni tipi in toposi so se navezovali na iste značajske in situacijske norme. Če pesemska besedila neapeljskih vilanel obravnavamo s stališča ponavljajočih se jezikovnih elementov, ugotovimo, da se v dikciji precej razlikujejo od lirskih izpovednih pesmi. V neapeljski vilaneli govoreči osebek nagovarja imaginarno osebo ali okolico neposredno, v tem trenutku in na tem mestu. Govor vključuje osebne in kazalne zaimke, hiperbolično izražanje, vprašalne prošnje in mašilne pogovorne izraze ter s tem simulira akcijo, značilno za dramska besedila. ${ }^{2}$ Motrenje s tega vidika razkriva, da besedila neapeljskih vilanel izgovarjajo tipizirani moški liki, katerih interpretacija z vključevanjem mimične

1 Donna G. Cardamone, Villanella - Villotta, Die Musik in Geschichte und Gegenwart. Sachteil 9, Kassel [...], Bärenreiter, 1998, stolp. 1518-1530; Donna G. Cardamone, Villanella, The New Grove Dictionary of Music and Musicians 26, 2. izdaja, London, Macmillan, 2001, str. 628-631. $\mathrm{V}$ razpravi je uporabljen poslovenjeni izraz neapeljska vilanela.

2 Donna G. Cardamone in Cesare Corsi, The Canzone Villanesca and Comic Culture: The Genesis and Evolution of a Mixed Genre (1537-1557), Early Music History 25 (2006), str. 82-92. 
igre in gestikulacije privzame izrazito komičen značaj. Ti dve značilnosti sta bistvena razločevalna elementa preprostih italijanskih pesmic, ki so se kot komična glasbena zvrst razširile tudi v dežele onstran italijanskega govornega področja. Čeprav primarni glasbeni viri ne pojasnjujejo značilnih izvajalskih aspektov, pa sinteza dosedanjih parcialnih analitičnih in tipoloških študij dopušča sklepanje, da srž neapeljske vilanele ok. leta 1570, navkljub njenemu poimenovanju, ni v narečnih posebnostih, temveč v komičnosti. Opisna naslovna oznaka je poznavalskim poslušalcem napovedovala pesmi duhovitih, zbadljivih in posmehljivih prispodob, ki jih bodo izzivalno dražile in nasmejale.

Običajno izrazno sredstvo neapeljske vilanele je karikiranje obstoječih literarnih konvencij po načinu burleskne poezije. ${ }^{3}$ Pogoste so sublimacije poželenja lirske poezije Petrarke in Bemba in hvale užitku ali spremembe gospe v izžeto babnico. Svojstvena nejasnost in skrivnostnost besedilnih sporočil neapeljske vilanele, prav tako kot burleskne poezije, izhaja iz dejstva, da se je posluževala kodiranega besednjaka in namigovanja na aktualne družbene prakse in mnenja. ${ }^{4}$ Pesniki neapeljskih vilanel so tako kot burleskni pesniki tipično preoblikovali ali popačili prvotni pomen posameznih besednih zvez in na ta način ustvarili dve pomenski ravni. Na prvi je pesnik na zabaven način ponudil opis nekega objekta ali robate dovtipe, drugi pomenski nivo pa je nasprotno obscen. Navedene trditve ilustrirajo tudi neapeljske vilanele Giacoma Gorzanisa (ok. 1530-po 1574), ohranjene v dveh beneških tiskih iz začetka sedemdesetih let 16. stoletja z naslovoma Il primo libro di napolitane che si cantano et sonano in leuto ${ }^{5}$ in Il secondo libro delle napolitane a tre voci, ${ }^{6} \mathrm{ki}$ jih preko naslovnikov uvodnih posvetil povezujemo s kulturnimi krogi notranjeavstrijskih dežel. ${ }^{7}$

Gorzanisove napolitane ${ }^{8}$ so $\mathrm{z}$ nekaj izjemami neposredne izpovedi razočaranih moških, namenjene molčeči ženski sogovornici ali občinstvu. Govorec - trpeči, prevarani ali poželjivi snubec - izpoveduje svojo srčno bolečino, obuja spomine ali fantazira o ljubezenskem srečanju, besedilo pa v zadnji kitici začini s pikro ali zbadljivo mislijo. Že samemu po sebi teatralnemu besedilu je Gorzanis z uglasbitvijo podal paleto iztočnic za komično interpretacijo. Poleg karikiranega podajanja posameznih besed ali besednih zvez je ponudil številne priložnosti za improvizirano mimiko in gestikulacijo, ki sooblikujejo šaljive, zabavne in zbadljive momente neapeljske vilanele.

Značilen besedilni tip Gorzanisovih napolitan je tožba razočaranega moškega, čigar čustveno stisko je povzročila zveza z nestanovitno žensko. Govorec svojo navidezno

3 Deborah Parker, Towards a Reading of Bronzino's Burlesque Poetry, Renaissance Quarterly 50 (1997), str. 1019-1020.

4 D. Parker, nav. delo, str. 1023-1024.

5 RISM B/I $1570^{32}$.

6 RISM A/I/3 G3036.

7 Giacomo Gorzanis, Il primo libro di napolitane che si cantano et sonano in leuto, Benetke, G. Scoto, 1570; Giacomo Gorzanis, Il secondo libro delle napolitane a tre voci, nuouamente poste in luce, Benetke, G. Scotto, 1571. Sodobna znanstvenokritična izdaja: Giacomo Gorzanis, Il primo libro di napolitane che si cantano et sonano in leuto (1570), Il secondo libro delle napolitane a tre voci (1571), ur. Alenka Bagarič, Monumenta artis musicae Sloveniae LI, Ljubljana, Muzikološki inštitut ZRC SAZU in SAZU, 2007.

8 Gorzanisova tiska nosita naslovno oznako »napolitane«, a je v drugi knjigi v posvetilu uporabil izraz »villanelle alla napolitana«. V razpravi je uporabljen splošni termin neapeljska vilanela, razen v primeru sklicevanja na posamezne Gorzanisove skladbe ali tisk v celoti. 
sogovornico - preračunljivo damo, ki je prelomila obljubo ljubimkanja - sumi prevare ali pa spozna, da je njuno ljubezensko razmerje končano. V zaporednih kiticah se njegova bridka izpoved ali obtožujoče izjave stopnjujejo do parodičnega učinka.

Zaničevalne obtožbe jeznih rogonoscev so omejene na lik »staruhe« (it. vecchia), ki nastopa kot varuhinja mladega dekleta oziroma zvodnica z nebrzdanim spolnim poželenjem. »Mala vecchia« ali »vecchia mezzana« je bila značilni motiv dve desetletji starejših zbirk neapeljskih vilanel, motivika pohotne starke pa je znana tudi iz literarne teme grajanja zlobnih stark v latinski in komično-realistični poeziji ter iz ljudskega običaja zasmehovanja stark in starcev, ki so bili prestari, da bi bili objekt spolnega poželenja. ${ }^{9} \mathrm{~V}$ Gorzanisovih napolitanah z motiviko »vecchie mezzane « opeharjeni snubec nagovarja občinstvo. Opisuje zvodničine prevare, jo zaničuje in svari pred njenimi goljufijami, pri čemer se ponujajo možnosti za slikovito govorjenje.

Med tožbami najdemo tudi izpovedi zapuščenih žensk (it. lamento della donna) ter samogovore, $v$ katerih trpeči ljubimec objokuje čutno razmerje $\mathrm{z}$ brezbrižno žensko ter vzklika Amorju, ki ga krivi srčnih bolečin. V tožbah v obliki monologa se govorec s svojo nesrečno ljubezensko prigodo obrača neposredno na poslušalce, jih svari in jim svetuje.

$\mathrm{V}$ serenadnih besedilnih tipih govorec nagovarja čutno izzivalno sogovornico. V nekaj primerih vzneseni snubci svoji mladi izbranki izpovedujejo ljubezen z opisovanjem njene podobe ali z zamišljanjem intimnega srečanja. V drugih trpinčeni snubec opisuje svoje bedno stanje $\mathrm{v}$ komičnih pogovornih izrazih in tarnajočih petrarkističnih paradoksih ter svojo izbranko hrepeneče roti pomoči.

V uglasbitvah teh besedil se Gorzanis ni izogibal postopkov, ki veljajo za izrazito neapeljske. To so na primer ozka lega treh visokih glasov, gibanje v vzporednih kvintah in postopno sestopanje melodije $\mathrm{v}$ zaključnih kadencah. Med prepoznavnimi parametri neapeljske vilanele šestdesetih let je melodija v najvišjem glasu, ki poteka v treh zaokroženih melodičnih frazah, kar tvori tridelno glasbeno obliko :A: :B: :C: vsake kitice besedila. V Gorzanisovih melodijah prepoznavamo nekatere stereotipne figure starejših neapeljskih skladateljev vilanel kot so urne pospešitve in upočasnitve tempa ali nenadne zaustavitve, menjevanje metričnega toka, raznolikost ritmičnih poudarkov ter duhovito krajšanje in ponavljanje besed. V kontekstu kratke pesemske kitice so te figure pogosto nesorazmerne in delujejo kot sredstvo ironičnega sporočanja solzavih vsebin. Čeprav besedilo beremo kot tožbo trpečega ljubimca, je z uglasbitvijo spremenjeno v posmehovanje.

Za poudarjanje komičnosti je Gorzanis pogosto razširil glasbeno podajanje zadnjega verza kitice ali refrena s pretiranim ponavljanjem posameznih besed, $\mathrm{z}$ upočasnitvijo ali pohitevanjem ritmičnega toka, s spremembo metruma ali s kombinacijo različnih parametrov. Napolitana L'altro giorno mi disse v izvirni dvodobni menzuri alla breve traja 17 tempusov oz. prav toliko dvocelinskih taktov $\mathrm{v}$ transkripciji ter poteka pretežno $\mathrm{v}$ tekočih minimah in semiminimah. $\mathrm{V}$ zadnjem verzu kitice besedilni tok zastane $\mathrm{z}$ vzklikanjem besede »va«, ki se v prvem podajanju verza ponovi devetkrat, v drugem pa celo štirinajstkrat. Ponavljanje je v tem kontekstu pretirano, saj skupno traja kar 5 taktov (notni primer 1). Poleg tega sta s ponavljanjem poudarjeni še besedi »donna stana« in »lasciami stare«, kar lahko prepoznamo kot povzetek sporočila (»stara zvodnica« - »pojdi proč« - »pusti

9 Cesare Corsi, Il tema della vecchia nella canzone villanesca tra "vituperium", charivari, teatro comico rinascimentale, Settimo Colloquio di Musicologia, Bologna, 21-23 novembre 2003. Abstracts, http://www.saggiatoremusicale.it/ (1. september 2008). 
me na miru«). V sledečih kiticah so izpostavljene besede »inviluppato«, »berteggiato« in »ladroncelle« (»zapletel«, »preslepila«, »zapeljivke«).

Prav tako nesorazmerni so vzkliki veselja in hvaležnosti Amorju v napolitani moralizirajočega in slavilnega značaja Non fu mai donna, ki obsega 10 tempusov v menzuri alla breve in $5 \mathrm{v}$ ternarnem proporcu oz. 15 taktov $\mathrm{v}$ transkripciji, od katerih jih samo 8 pripada podajanju začetnega verznega para, preostali pa refrenski vrstici. V igrivo vijugavem neizrazitem melodičnem obrisu refrena prevlada vzklik »e mi rallegro« (»to me veseli«), ki se $\mathrm{v}$ dvodelnem metru ponovi trikrat, $\mathrm{v}$ ternarnem proporcu $\mathrm{v}$ poudarjenem punktiranem ritmu pa še štirikrat (notni primer 2). V izvirniku je zapisan s počrnjenimi notami.

Vzdihi in roteče prošnje so uglasbeni v daljših notnih vrednostih, ki so kontrastne predhodnemu ritmičnemu toku. Medmetni vzkliki in bolestno tarnanje so dvigajoče se raztegnjene figure, govorčevo rotenje pa je običajno izraženo s spuščajočimi se počasnimi toni. Začetni toni napolitane Donna gentil non so, na primer, potekajo v tekočih semiminimah. Gibanje se upočasni z vzdihi refrena »O, vis'adorno« (»o prelepo obličje«) z naraščajočo melodično linijo in z zaključno vrstico »habbi pietà di me tuo servitore« (»usmili se mene služabnika«), podloženo spuščajočim se minimam. Pri tem je prvi zlog besede »pietà« raztegnjen na semibrevis in zato pretirano poudarjen, posmehljiv učinek pa dodatno okrepi še vztrajanje zaporednih besedilnih zlogov na isti tonski višini, kar izstopa iz poteka celotne skladbe (notni primer 3). V napolitani Alma perché t'affliggi je vzklik »Ahime!« (»joj«) z začetka refrena postavljen na zaporedno vedno višji ton, solzavost glasu govorca pa odslikavajo vmesne pavze. Sledi vprašujoča prošnja, v kateri je $\mathrm{z}$ razdelitvijo verzne vrstice $\mathrm{v}$ dva dela poudarjena beseda »ljubiš« (»perché non ami 'l tuo servo fedele?«, »zakaj ne ljubiš zvestega služabnika?«).

$\mathrm{V}$ repertoarju Gorzanisovih napolitan najdemo številne besedne ponovitve, ki v kontekstu kratke pesmi delujejo kot trenutni ekspresivni efekti, primerljivi s tonskim slikanjem madrigalističnih skladateljev. V napolitani Da che si parte il sol ilustrira dolžino neprespane noči bolestnega govorca vztrajno ponavljanje besed »tutta la notte« (»Vso noč«), ihtenje pa zasople pavze ob besedi »sospiro« (»vzdihujem«; notni primer 4).

V nekaj napolitanah je hitro menjavanje ritmičnega toka in tempa brez spreminjanja menzurnih znakov v izvirnem zapisu nakazano z drobljenjem verzne vrstice na krajše odseke, ločene s pavzami ali znakom za ponavljanje. V napolitani Nessuno ti cognosce se upočasnitvam in pohitevanjem tempa posameznih odsekov v zadnji verzni vrstici pridruži še pohitevajoče ponavljanje besed »santa ti fai« (»delaš se sveto《) v načinu odmeva (notni primer 5). Hitro spreminjanje ritmičnega toka, ki daje vtis pohitevanja in upočasnjevanja, zaznamuje tudi serenado Questi capelli d'oro v alla breve menzuri. Prva vrstica vsake od štirih kitic opisuje izbrankino obličje: lase, čelo in trepalnice, oči ter nos in ustnice. Začenja se v dolgih in poudarjenih semibrevis nasproti srednji vrstici, ki teče pretežno v minimah. Zadnja vrstica je razdeljena na pohitevajoč začetni odsek v semiminimah in upočasnjen sklepni del za korono $\mathrm{v}$ izrazito raztegnjenih semibrevis in brevis (notni primer 6).

Parodični učinek izzove tudi menjava mere, ki v uglasbitvah praviloma nastopi po začetnem paru enajstercev. Kontrastno metrično gibanje poteka istočasno v počasnejšem tempu in na tak način poudari pomenskost zadnjega verza. V napolitani Duca vi voglio dir refren v proporcu sesquialtera, ki nakazuje delitev semibrevis na tri minime v nasprotju s predhodno delitvijo na dve, odkrito namiguje na dejanje spolnega akta (notni primer 7).

Napolitani Tu m'amasti un tempo v tridobni menzuri daje zbadljiv ton že poskočni 
ritem, ki je v izvirniku naznačen z zapisom s počrnjenimi notami. Izrazito porogljiv preobrat pa se zgodi v refrenu s ponavljanjem besed »se vuoi« (»če želiš«) s poudarjeno razvlečenim diftongom ter hipnim miselnim in ritmično-melodičnim obratom (notni primer 8). Odklon od ustaljene tridelne forme za kitice iz treh vrstic, ki jo v repertoarju neapeljske vilanele zasledimo po letu 1560, je Gorzanis uporabil z namenom, da bi intenziviral govorčevo razočaranje. Dvodelno obliko je izdelal z združitvijo prve in druge vrstice besedila.

Poleg posmehljivega in porogljivega glasbenega podajanja besed se govornik pogosto metaforično poigrava $\mathrm{z}$ antitezami kot so živeti - umirati ali goreti - zmrzovati ter drugimi besednimi zvezami, ki v določenem kontekstu prikazujejo erotično vsebino. Pod površjem na videz lahkotne ljubezenske lirike prepoznavamo plasti dvoumnega izražanja in skritih dvojnih pomenov evfemističnega besednjaka italijanske burleskne poezije 16. stoletja. Za večino Gorzanisovih napolitan serenadnega tipa se zdi, da nagovarjajo kurtizano, poleg naštevanja čutnih delov njenega telesa pa se govornik poigrava $\mathrm{z}$ besedami, ki nedvomno namigujejo na spolnost.

Besedila Gorzanisovih napolitan izvabljajo izvajalske geste, primerljive z edinim znanim podrobnejšim opisom prepevanja neapeljske vilanele v njegovem času. Gre za opis nastopa Orlanda di Lassa, ki je v igri, označeni kot »Comedia all'improuiso alla Italiana« v treh dejanjih na vrhuncu slovesnosti ob poroki mladega bavarskega vojvode Wilhelma V. z Renato Lorensko v Münchnu 8. marca 1568 samospremljano zapel eno najbolj priljubljenih vilanel stoletja Chi passa per questa strada.${ }^{10}$ Opis je v kroniki slavja v obliki dialoga med izmišljenima sogovornikoma Mariniom in Fortuniom še istega leta priskrbel eden od protagonistov Massimo Troiano. ${ }^{11}$ Razkril je, da sta si z Lassom

${ }^{10}$ Wolfgang Boetticher, Orlando di Lasso und seine Zeit, 1532-1594, Kassel in Basel, Bärenreiter, 1958, str. 332. Vilanela Chi passa je bila leta 1557 objavljena v Doricovi antologiji triglasnih vilanel (RISM B/I $1557^{19}$ ) ter kot štiriglasna priredba v prvi zbirki serije Villotte del fiore Filippa Azzaiola pri Gardanu (RISM B/I $1557^{18}$ ). Vsebino zbirke je v preurejenem vrstnem redu ponatisnil Scotto (RISM 156011), ki je Chi passa postavil na prvo mesto. Scottovi izdaji so sledile še tri identične beneške izdaje, dve leta 1564 (Scotto, RISM B/I 1564 ${ }^{14 a}$ in Gardano, RISM B/I $1564^{14}$ ) in ena 1566 (Rampazetto, RISM B/I 15664). Prim. Jane A. Bernstein, Music Printing in Renaissance Venice: The Scotto Press (1539-1572), New York in Oxford, Oxford University Press, 1998, str. 557; Mary S. Lewis, Antonio Gardano, Venetian Music Printer 1538-1569: A Descriptive Bibliography and Historical Study 3 (1560-1569), New York in London, Garland in Routledge, 2005, str. 212-213. Najdemo jo tudi pri Gorzanisu in sicer v drugi knjigi lutenjskih tabulatur iz leta 1563: prvič v nizu treh metrično in ritmično različnih stavkov passemzzo padoana - saltarello, zgrajenih na istem vzorcu (O perfida che sei), in drugič kot plesno skladbo z naslovom Padoana detta Chi passa per questa strada.

${ }^{11}$ Massimo Troiano, Discorsi delli triomfi, giostre, apparati, e delle cose più notabile fatte nelle sontuose nozze, dell illustrissimo et excellentrissimo Signor Duca Guglielmo, primogenito del generosissimo Alberto quinto, conte Palatino del Reno, e Duca di Baviera alta e bassa, nell' anno 1568 à 22. di febraro, München, Adam Montano, 1568, str. 184-185. Dopolnjena izdaja je izšla pod naslovom Dialoghi ne'quali si narrano le cose più notabili fatte nelle Nozze dello Illustriss. \& Eccell. Principe Guglielmo [...] tradotti nella lingua castigliana, Benetke 1569. Prim. James Haar, Munich at the Time of Orlande de Lassus, The Renaissance: from the 1470s to the end of the 16th century, ur. Iain Fenlon, Basingstoke, Macmillan, 1989, str. 245-256; Martha Farahat, Villanescas of the Virtuosi: Lasso and the 'Commedia dell'arte', Performance Practice Review 3 (1990), str. 123-130; M. A. Katritzky, Orlando di Lasso and the Commedia dell'arte, Orlando 
dan pred uprizoritvijo skupaj zamislila temo in scenarij commedie dell'arte, v kateri je nastopalo 10 značajev. S skupino italijanskih glasbenikov sta oba nastopila v več vlogah. Lasso je v vlogi pohotnega senilnega beneškega trgovca Pantalona (»Magnifico Messer Pantalone de Bisognosi«) svoji izbranki, trmasti kurtizani Camilli, ki se je skrivala za zastrtim oknom, v prvem dejanju najprej zapel omenjeno vilanelo, pri čemer se je sam spremljal z lutnjo, nato pa patetično vzdihoval. Njegove strastne prošnje za zadovoljitev so izzvale vrsto ekspresivnih gest, ki so namigovale tako na jalovo željo kot tudi na prevaro. Po poročanju Troiana je Lasso dvakrat zapel vilanelo Chi passa, nato pa odložil lutnjo in začel objokovati svojo nesrečno ljubezen z besedami: »O ubogi Pantalone, ki ne more hoditi po tej cesti, ne da bi napolnil zrak z vzdihljaji in omočil tal s svojimi solzami« ${ }^{12}$ Od trenutka, ko je na oder stopil Lasso, preoblečen v Magnifica, v srajci iz rdečega satena, rdečih beneških nogavicah, v do tal segajočem črnem plašču in z masko na obrazu, so se vsi krohotali in dokler je bil na odru, se ni slišalo drugega kot smeh. Troiano je še pripomnil, da so bile navzoče vse plemenite dame in četudi jih večina ni razumela besed, sta »Messer Magnifico« in njegov »Zanni« igrala tako dobro in primerno, da so jih od smeha bolele čeljusti. ${ }^{13}$

$\mathrm{V}$ besedilih treh Gorzanisovih napolitan najdemo poleg tipiziranih anonimnih značajev tudi onomastične navedbe, ki dovoljujejo povezovanje s konkretnimi zgodovinskimi osebami ter sklepanje o priložnostih za njihovo izvajanje. Napolitana Marta gentile iz Gorzanisove druge knjige opeva komorno glasbenico na dunajskem cesarskem dvoru, ki sta jo kot pevko in instrumentalistko $v$ francoskih chansonah in latinskih motetih slavila flamska skladatelja Séverin Cornet in Philippe de Monte, omenja pa jo tudi latinski epigram v rokopisnem opisu alegoričnega turnirja ob poroki avstrijskega nadvojvode Karla II. z Marijo Bavarsko na Dunaju. ${ }^{14}$ Ker je bila pesem o glasbenici Marti objavljena v knjigi, ki jo je Gorzanis posvetil nadvojvodi Karlu kratko pred poročnimi slovesnostmi, ki so se na Dunaju in v Gradcu zvrstile med 24. avgustom in 17. septembrom 1571 (posvetilo je bilo podpisano 15. julija $1571 \mathrm{v}$ Benetkah), so se v literaturi pojavila ugibanja, da bi tudi Gorzanis utegnil sodelovati pri številnih glasbenih dogodkih. ${ }^{15}$ Gorzanis je v uvodnih vrsticah posvetila zapisal, da posveča knjigo neapeljskih vilanel nadvojvodi zaradi spomina in navezanosti, ter izrazil željo, da bi mu v prihodnosti služil. Vendar se iz formulacije posvetila da jasno razbrati, da je v preteklosti zanj že igral. Posvetilo je, bolj kot poklon

di Lasso in der Musikgeschichte. Bericht über das Symposion der Bayerischen Akademie der Wissenschaften, München, 4.-6. Juli 1994, ur. Bernhold Schmid, München, Bayerischen Akademie der Wissenschaften, 1996, str. 145.

${ }^{12}$ M. Troiano, Discorsi delli triomfi, str. 185.

${ }^{13}$ M. A. Katritzky, nav. delo, str. 136.

${ }^{14}$ Robert Lindell, Marta gentile che 'l cor m'ha morto. Eine unbekannte Kammermusikerin am Hof Maximilians II, Musicologica Austriaca 7 (1987), str. 62-68; Karl Vocelka, Habsburgische Hochzeiten 1550-1600: kulturgeschichtliche Studien zum manieristischen Repräsentationsfest, Veröffentlichungen der Kommission für neuere Geschichte Österreichs 65, Wien [...], Böhlau, 1976, str. $168-182$.

${ }^{15}$ R. Lindell, nav. delo, str. 59-68; Robert Lindell, The Wedding of Archduke Charles and Maria of Bavaria in 1571, Early Music 18 (1990), str. 257; Dinko Fabris, The Role of Solo Singing to the Lute in the Origins of the Villanella alla Napolitana, c. 1530-1570, Gesang zur Laute, ur. Nicole Schwindt, Trossinger Jahrbuch für Renaissancemusik 2, Kassel [...], Bärenreiter, 2002, str. $140-141$. 
vladarju, samopriporočilo dvornemu plemstvu in, prej kot glasba ob priliki poročnih slovesnosti, glasbena knjiga, ki prinaša pesmi za zabavo v zasebnih krogih.

Gorzanis je bil med glasbeniki, ki so v šestdesetih letih obiskovali dunajski cesarski dvor v upanju na priložnostno ali celo redno zaposlitev. Slepi lutnjist ni mogel zasedati mesta dvornega glasbenika, zato je kot potujoči virtuoz nenehno iskal priložnostno delo. Iz posvetil štirih tiskov lutenjskih tabulatur izvemo, da je igral za naslovnike na Kranjskem, omenjal pa je tudi številne prijatelje - glasbene poznavalce (»miei amici periti dell'arte Musica $)$ in slavne gospode in zaščitnike (»molti miei Illustri Signori et Patroni«), čeprav jih ni imenoval.

$\mathrm{Na}$ videz neznatna notica $\mathrm{v}$ rokopisnem seznamu cesarjevih osebnih izdatkov iz obdobja od januarja 1568 do decembra 1570, ki ga hrani Avstrijska nacionalna knjižnica na Dunaju, ${ }^{16}$ razkriva, da se je Gorzanis že leta 1568 zadrževal na Dunaju, saj ga je cesar Maksimilijan II. za neznano uslugo 11. maja poplačal s 40 tolarji. ${ }^{17}$

Slovesnosti ob dvorni poroki na Dunaju in v Gradcu leta 1571 so bile dokumentirane $\mathrm{v}$ kar sedmih tiskanih in izčrpnem rokopisnem delu, vendar nobeno ne podaja tako podrobnih opisov glasbenih izvedb, kot jih je zabeležil Massimo Troiano po poročnih slovesnostih v Münchnu leta $1568 .{ }^{18} \mathrm{Kljub}$ temu o veličastnosti glasbe ne gre dvomiti, saj so za izvedbe skrbeli kar trije eminentni korpusi glasbenikov s svojimi vodji: bavarski

${ }^{16}$ A-Wn, Codex 9089. Tabulae codicum manu scriptorum praeter Graecos et Orientales in Bibliotheca Palatina Vindobonensi asservatorum 6 (Cod. 9001 - 11500), Dunaj, Academia caesarea Vindobonensis, Carl Gerold, 1873, str. 15.

${ }^{17}$ Joseph Chmel, Die Handschriften der k. k. Hofbibliothek in Wien 2, Dunaj, Carl Gerold, 1841, str. 118. Na podatek je opozoril Robert Lindell, New Findings on Music at the court of Maximilian II, Kaiser Maximilian II. Kultur und Politik im 16. Jahrhundert, ur. Friedrich Edelmayer in Alfred Kohler, Dunaj, Verlag für Geschichte und Politik, München, R. Oldenbourg Verlag, 1992, str. 233-234. Lindell je domneval, da je bila nagrada izplačana za krajšo skladbo ali pa je bila zgolj plačilo daljšega zadrževanja na cesarskem dvoru. Določnejši odgovor na to vprašanje morda ponuja notica iz nepopolno ohranjenega najstarejšega rokopisnega popisa dunajske dvorne knjižnice Huga Blotiusa iz leta 1576 (Codex 13525). V kritični izdaji prepisa tega dela, ki podaja tudi današnje številčenje rokopisnih kodeksov, je za Blotiusovo signaturo R 4834 prepisana njegova navedba in opis (»Di Jacomo Gorzanis Cittadino di Trieste vel al l'Imperatore Massimiliano secondo, in $8^{\circ}$ scritti à penna«), razrešitev v današnjo signaturo (A-Wn, Codex 9871, 23v) pa žal ne ustreza opisanemu dokumentu. V tabeli konkordanc današnje številčenje ni podano, urednik pa je tudi izrazil dvom o rokopisnem tipu gradiva. Vsekakor je zmedo povzročil že Blotius, ko je prvotno številko po letu 1576 zamenjal z novo. Ne glede na nekdanje in današnje številčenje bibliografskih enot dunajske dvorne knjižnice je iz Blotiusovega inventarnega vpisa razvidno, da je imel v rokah rokopis Gorzanisovih skladb v oktavnem formatu, poklonjen cesarju. Prim. Tabulae codicum manu scriptorum praeter Graecos et Orientales in Bibliotheca Palatina Vindobonensi asservatorum 7 (Cod. 11501-14000), Dunaj, Academia caesarea Vindobonensis, Carl Gerold, 1875, str. 228; Tabulae codicum manu scriptorum 6, str. 103; Herman Menhardt, Das älteste Handschriftenverzeichnis der Wiener Hofbibliothek von Hugo Blotius 1576. Kritische Ausgabe der Handschrift Series nova 4451 vom Jahre 1597 mit vier Anhängen, Dunaj, Rudolf M. Rohrer, 1957, str. 67.

${ }^{18}$ Heinrich Wirri, Ordenliche Beschreibung des Christlichen, Hochlöblichen vnd Fürstlichen Beylags oder Hochzeit, so da gehalten ist worden durch den Durchleuchtigisten [...] Herrn Carolen, Ertzhertzog zu Osterreich [...] mit dem Hochgebornen Fräwlein Maria, geborne Hertzogin zu Bayrn, Dunaj, B. Eber, 1571; Wenzel Sponrib, Warhaffte Beschreibung, was von der fürstl. Durchleuch. Ertzhertzogen Carls zu Oesterreich etc. Hochzeitlicher haimfuerung in 
dvorni glasbeniki z Orlandom di Lassom, glasbeniki cesarske kapele s Philippom de Montejem in glasbeniki nadvojvode Karla z Annibalom Padovanom. ${ }^{19}$ Poleg teh so bili prisotni tudi številni drugi italijanski glasbeniki, med njimi Giulio Cesare Brancaccio in Alessandro Striggio, pa tudi Maddalena Casulana, ki se je na cesarskem dvoru dokumentirano zadrževala v letih 1571 in 1572 . Nuncij Delfino je v poročilu o ceremonialu na dan poroke na Dunaju zapisal, da se je v cerkvi pel Te Deum, med kosilom, ki je sledilo, pa so igrali »diversi concerti«, beneški poslanik pa je poročal, da jih je zabavala razkošna cesarjeva glasba. ${ }^{20}$

$\mathrm{V}$ nizu dogodkov, ki naj bi se v pripravah in realizaciji v veliki meri zgledovali po münchenskih in so obsegali tako turnirje in parade kot plese in lov, bi prilike za prepevanje neapeljskih vilanel pričakovali v okvirih italijanske komedije. ${ }^{21}$ Čeprav jih opisi ne navajajo, je v dvornih plačilnih knjigah dvakrat zabeležen izdatek po naročilu cesarja v višini 50 zlatnikov za italijanske komedijante Giovannija Tabarina, prvič 6. in drugič 26. septembra $1571 .^{22}$

Gostovanja italijanskih zabavljivcev so tako v Münchnu kot tudi na dvorih avstrijskih Habsburžanov v virih zabeležena in v strokovni literaturi identificirana že od srede 16. stoletja dalje. ${ }^{23}$ Najprej so se pojavili posamezniki, pretežno akrobatski umetniki (it. buffoni), kmalu pa tudi številnejše gledališke skupine (it. commici). Med izdatki dunajskega dvora so zabeležena vsakoletna plačila italijanskim komedijantom od decembra 1568 dalje. ${ }^{24}$ Prvi je v času deželnega zbora v Linzu omenjen prav Benečan Giovanni Tabarino, ki so mu po cesarjevem naročilu izročili 30 tolarjev, nato pa je cesarskemu dvoru sledil na vseh odmevnih državniških dogodkih. ${ }^{25}$

Vzgibe za nagel prihod italijanskih komedijantov pa gre poleg največkrat omenjane geografske bližine iskati predvsem v tesnih dinastičnih zvezah Habsburžanov s severnoitalijanskimi vojvodskimi hišami v šestdesetih letih. Avstrijski Habsburžani so namreč sklenili družinske vezi prav s tistimi italijanskimi dvori, ki se jim pripisuje vodilna vloga v pokroviteljstvu poklicnih gledaliških družin in kulture praznovanja (Ferrara, Mantova in Firence). ${ }^{26}$

M. A. Katritzky je v rekonstrukciji odločilnih dejavnikov prenosa commedie dell'arte

der Hauptstädt Grätz in Steyer vom 17. Augusti biß auff den 8. September von Porten und andern Triumphirenden zierligkhaiten zuegerichtet, Gradec, Z. Bartsch, 1572.

${ }^{19}$ Adolf Sandberger, Beiträge zur Geschichte der bayerischen Hofkapelle unter Orlando di Lasso 3 (Dokumente), Leipzig, Breitkopf \& Härtel, 1895, str. 307; Horst Leuchtmann, Orlando di Lasso 1 (Sein Leben), Wiesbaden, Breitkopf \& Härtel, 1976, str 158.

${ }^{20}$ K. Vocelka, nav. delo, str. 90; Joseph Fiedler, Relationen venetianischer Botschafter über Deutschland und Österreich im sechzehnten Jahrhundert, Dunaj, Hof- und Staatsdruckerei, 1870, str. 286.

${ }^{21} \mathrm{~K}$. Vocelka, nav. delo, str. 55-63.

${ }^{22}$ Walter Pass, Musik und Musiker am Hof Maximilians II., Tutzing, Hans Schneider, 1980, str. 298-299; K. Vocelka, nav. delo, str. 84; Otto G. Schindler, Commedia dell'arte am Josefsplatz und das Phantom der Bibliothèque de l'Opéra, Biblos 45 (1996), str. 71-72.

${ }^{23}$ M. A. Katritzky, nav. delo, str. 149.

${ }^{24}$ Luigi Rasi, I comici Italiani: biografia, bibliografia, iconografia, Firenze, Fratelli Bocca, 1905, str. 555-560; O. G. Schindler, nav. delo, str. 63-69.

${ }^{25}$ J. Chmel, nav. delo, str. 121; O. G. Schindler, nav. delo, str. 69-71.

${ }^{26}$ O. G. Schindler, nav. delo, str. 63. 
iz Italije na bavarski dvor izhajala iz predpostavke, da je izvor commedie dell'arte tesno povezan z začetki poklicnega igranja in s porajanjem poklicnih igralskih družin v Italiji sredi 16. stoletja, ki so, v nasprotju z izvajanjem napisane commedie erudite v ljubiteljskih krogih, improvizirano igrale po kratko zasnovanih zgodbah ali scenarijih. V nagovarjanju občinstva so k prvotnemu jedru maskiranega para gospodar - služabnik (Magnifico Zanni), okoli katerega se je razpletala osrednja zgodba, dodajali različne veščine, kot so akrobatika, vizualni humor, glasbene točke, ples in petje (it. lazzi). ${ }^{27}$

Izmed virov o italijanskih renesančnih slavjih, ki najprepričljivejše kažejo na kulturno izmenjavo med Bavarsko in Italijo v letih neposredno pred 1568, je M. A. Karitzky izpostavila dnevnik bavarskega princa Fedinanda, ki beleži dogodke s potovanja v Italijo med 20. novembrom 1565 in 2. februarjem 1566, kjer je zastopal starša na poroki svoje tete, avstrijske princese Johanne z vojvodo Francescom de Medici, ter obiskal njeni sestri Eleonoro, poročeno z mantovskim vojvodom (1561) in Barbaro, ki je bila sredi praznovanja poroke s ferrarskim vojvodom. ${ }^{28}$

Omeniti pa velja tudi podatek, podan v Troianovem opisu münchenskih poročnih slovesnosti, po katerem so poleg commedie dell'arte, ki so jo uprizorili vojvodovi glasbeniki, prisotni videli še tri predstave značilnega komičnega para Zanni - Pantalone, in sicer na banketu na sam poročni dan, 22. februarja 1568, na maškaradi in na banketu po jezuitski drami v petek, 27. februarja, na katerem je smešno vedenje treh mask nasmejalo vse zbrane, tudi tiste, ki niso razumeli besed. ${ }^{29}$ Verjetno je, da so se na podoben način zabavali tudi na banketih na Dunaju in v Gradcu ob poroki nadvojvode Karla in Marije Bavarske. V tem oziru je navedeni podatek pomenljiv predvsem kot potrditev poveličevanja in ovekovečenja Habsburžanov z italijanskim komičnim gledališčem.

Podobno rekonstrukcijo, kot jo je v primeru širjenja commedie dell'arte na bavarski dvor predlagala M. A. Katritzky, lahko izdelamo v primeru seznanjanja s specifičnimi italijanskimi oblikami zabave in njihovega sprejemanja v habsburških dvornih krogih ob izteku šestdesetih let. Osnova zanjo je edinstveno zaporedje dogodkov v maju leta 1569, ko se je nadvojvoda Karel ob povratku z uradnega obiska na španskem dvoru v Madridu, kamor se je po pooblastilu svojega brata in cesarja Maksimilijana II. podal 24. oktobra 1568, mudil v Firencah, Ferrari, Mantovi in Benetkah.

O veličastnem sprejemu nadvojvode Karla v Firencah se je ohranil opis v slavilnem tisku, ki poveličuje sijajnost in velikodušnost firenškega vojvode in lokalnega plemstva. ${ }^{30}$ Knjiga govori o uprizoritvi komedije La vedova Giovanbattista Cinija in njegovih intermedijev, za katere je glasbo napisal Alessandro Striggio, ter o maškaradi na firenških ulicah. ${ }^{31}$ Poleg tega se je v pismih nadvojvodovega vicekanclerja Janeza Kobencla s Proseka,

${ }^{27}$ M. A. Katritzky, nav. delo, str. 133-134.

${ }^{28}$ M. A. Katritzky, nav. delo, str. 149-152; M. A. Katritzky, The Florentine entrata of Joanna of Austria and Other entrate Described in a German Diary, Journal of the Warburg and Courtauld Institutes 59 (1996), 148-173.

${ }^{29}$ M. Troiano, Dialoghi, str. 68v, 88v in 122v. Prim. M. Farahat, nav. delo, str. 124; M. A. Katritzky, Orlando di Lasso and the Commedia dell'arte, str. 138.

${ }^{30}$ Raccolto delle feste fatte in Fiorenza dalli ill.mi et ecc.mi nostri Signori e padroni, il Sig. Duca, et il Sig. Principe di Fiorenza et di Siena, nella venuta del Serenissimo Arciduca Carlo d'Austria per honorarne la presenza di sua Altezza, Firence, I Giunti, 1569.

${ }^{31}$ Intermedije opisuje tudi Giovanni Passignani, Descrittione dell'intermedii fatti nel felicissimo palazo del Gran Duca Cosimo, et del suo illustris[simo] figliuolo principe di Firenze, et di 
poslanih nadvojvodi Ferdinandu Tirolskemu v Innsbruck, ohranilo izjemno zanimivo in za kulturno zgodovino dragoceno pričevanje, ki podaja opis Karlovega srečanja z italijansko komedijo, intermediji in praznovanji z drugačnega izhodišča presojanja. ${ }^{32}$

Po Kobenclovem pripovedovanju so nadvojvodo najveličastneje sprejeli na medičejskem dvoru v Firencah, kjer sta ga pričakala Cosimo de Medici, njegov sin Francesco ter njegova žena, najmlajša Karlova sestra Johanna. Kobencl je zapisal, da se v Firencah noben dan ne sklene brez plesa. Posebej slikovit je njegov opis komedije, ki se je začela v nedeljo 3. maja ob treh popoldan, ogledalo pa si jo je okrog 1.000 ljudi, med njimi 300 plemičev, ki so po predstavi ostali na dvorni pojedini in plesu. Kobencl je poročal, da zgodba o dekletu (»Medl«), ki je obljubljala poroko trem snubcem (Neapeljčanu, Sicilijancu in Firenčanu), a jo je nazadnje onečastil Magnifico, ni bila nič posebnega, močan vtis pa so pustili intermediji (»Intermedia«). V kratkem opisu le-teh je naštel tudi nekaj všečnih pevskih točk. ${ }^{33}$ Zapisal je še, da se prisotni niso mogli načuditi lepoti in spretnosti oseb, bogov, angelov in drugih nastopajočih, ter dodal, da se nebo, oblaki, bogovi in angeli niso mogli bolje predstavljati človeškim čutom.

Glasbenih točk intermedijev ne moremo povezati z vsebinskim okvirjem neapeljskih vilanel, nasprotno pa komedija citira besedila treh, ki jih najdemo tudi v ohranjenih glasbenih tiskih. V tretjem dejanju komedije mladi Neapeljčan (»Signor Cola Francesco «) razkazuje svoj pesniški in pevski talent s »petrarkistično pesmijo v neapeljski tradiciji«, za katero razloži, da se zgleduje po pesmi Giovannija Leonarda dell'Arpa, ki se glasi »Villanella crudel mi fai morire con s'uocchi, et con sa bocca saporita, tu mi dai morte ahime, tu mi dai vita« ${ }^{34} \mathrm{~V}$ četrtem dejanju Neapeljčan in sicilijanski vojak (»Fiaccavento«)

Siena, per honorar la illustris[sima] presenza della [...] altezza dello eccellentissimo arciduca d'Austria, Firence, B. Sermartelli, 1569. Prim. Alfred Einstein, Italienische Musik und italienische Musiker am Kaiserhof und an den erzherzoglichen Höfen in Innsbruck und Graz, Studien zur Musikwissenschaft 21 (1934), str. 12; Nino Pirrotta in Elena Povoledo, Music and Theatre from Poliziano to Monteverdi, Cambridge, Cambridge University Press, 1982, str. 188-193.

32 Johann Loserth, Die Reise Erzherzog Karls II. nach Spanien (1568-1569), Mittheilungen des historischen Vereins für Steiermark 54 (1896), str. 162-166.

33 J. Loserth, nav. delo, str. 194-195.

${ }^{34}$ Giovanni Battista Cini, La vedova commedia rappresentata à honorare del Serenissimo Arciduca Carlo D'Austria nella venuta sua in Fiorenza l'anno MDLXIX, Firence, I Giunti, 1569, str. 94-95. Vilanelo z začetnim verzom »Villanella crudel mi fai morire « najdemo v dveh Scottovih tiskih in sicer v peti knjigi zbirke Villotte alla napoletana a tre voci de diversi (RISM B/I $1566^{5}$ in ponatisu RISM B/I $1570^{20}$ ) ter v Scotovi knjigi Corona, il secondo libro delle canzoni alla napolitana a tre voci iz leta 1571 (RISM A/I S2625), a se besedili prve kitice razlikujeta od citiranega že v drugem verzu. Repertorio della Poesia Italiana in Musica, 1500-1700 (v nadaljevanju RePIM), podatkovna zbirka, ur. Angelo Pompilio, Università di Bologna, Dipartimento di Musica e Spettacolo, dostopno na: http://repim.muspe.unibo.it. (1. oktober 2008) Prim. N. Pirrotta in E. Povoledo, nav. delo, str. 188. Pirrottova navedba je nepopolna in deloma netočna. 
zapojeta vilanelo »S'io havissi tantillo, tantillo di speranza ${ }^{35}$ Neapeljčan pa še »Chisso mussillo d'oro «. ${ }^{36}$

Dejstva se kažejo kot ključna za razumevanje širitve in poistovetenja Avstrijcev s svojstvenimi italijanskimi oblikami reprezentacije. Poleg samega srečanja nadvojvode Karla in njegovih dvorjanov z italijansko komično kulturo je z gledišča širitve neapeljske vilanele v avstrijske dežele pomenljiva zlasti sižejska podobnost med zabeleženo komedijo in tipično neapeljsko vilanelo, ki pripoveduje zgodbo prevaranega ljubimca in nezveste izbranke, prav tako pa tudi pritrdilni odziv gledalcev iz tujine.

Iz ohranjenih virov je razvidno stalno izmenjevanje mnenj o različnih umetniških delih med tremi habsburškimi in dvema bavarskima vladarjema, pa tudi posojanje knjig, glasbenih del in prehajanje umetnikov, ki se je po letu 1571 še okrepilo. Največkrat so govorili o cerkvenih skladbah, o neapeljskih vilanelah pa viri molčijo. ${ }^{37}$ Pa vendar se je na bavarskem dvoru leta 1568 zbralo več skladateljev, ki so se zapisali v zgodovino zvrsti z objavami skladb v dveh beneških antologijah sredi šestdesetih let ${ }^{38}$ ali s samostojnimi tiski. Med njimi so bili poleg že omenjenih Massima Troiana in Orlanda di Lassa še Ivo de Vento, Gioseffo Guami in Francesco Londariti. Lasso je veliko let pozneje zbral svoja »mladostna dela« v knjigi z naslovom Libro de villanelle, moresche, et altre canzoni a. 4. 5. 6. \& 8. voci, ${ }^{39} \mathrm{ki}$ jo je pospremil s posvetilom vojvodi Wilhelmu V. ${ }^{40}$ Ne nazadnje pa je od leta 1573 na dvoru vojvode Albrehta V. deloval tudi italijanski skladatelj Cosimo Bottegari, po katerem se je ohranila rokopisna zbirka, okrašena z grbom bavarskih nadvojvod, s pretežno stenografsko zabeleženimi madrigali, lahkotnimi kanconami in neapeljskimi vilanelami za petje ob spremljavi lutnje. ${ }^{41}$

Massimo Troiano se je bavarskim glasbenikom najverjetneje pridružil leta 1568 ter ostal z njimi do pomladi 1570, ko je zaradi umora svojega kolega na hitro zapustil dvor v Landshutu in so se za njim zabrisale vse sledi. ${ }^{42} \mathrm{~V}$ tem času je v Benetkah izdal tri knjige neapeljskih vilanel, od katerih je eno naslovil na cesarjevega komornika Juana Manriquea. V posvetilu, podpisanem 20. januarja 1969 v Münchnu, je zapisal, da so

${ }^{35}$ G. B. Cini, nav. delo, str. 119. Triglasna vilanela »Si havessi tantillo di speranza« je bila natisnjena v knjigi Il primo libro de canzone napolitane a tre voci G. L. Primavere iz leta 1565 (RISM B/I $1565^{17}$ ) in v leto dni mlajšem ponatisu (RISM B/I $1566^{14}$ ), kjer je kot avtor naveden Rinaldo Burno. Z naslovom »S'io havesse tantillo di speranza« je bila kot delo neznanega avtorja objavljena tudi v njegovi tretji knjigi vilot »alla napolitana« iz leta 1570 (RISM B/I 1570 ${ }^{31}$ ), ki je ponatis neohranjene zbirke iz leta 1566. RePIM; N. Pirrotta in E. Povoledo, nav. delo, str. 188-189. Pirrotta povzema podatke po Crocejevi izdaji komedije iz leta 1953, ki navaja kot avtorja Dell'Arpo.

${ }^{36}$ G. B. Cini, nav. delo, str. 132. Tretja citirana vilanela je bila objavljena v prvi knjigi triglasnih kancon neapeljskega skladatelja Michela Califana iz leta 1567 (RISM A/I C72a). RePIM.

${ }^{37}$ A. Sandberger, nav. delo, str. 305-308; H. Leuchtmann, nav. delo, str. 162; Hanna Schäffer, Maria von Bayern und die Musik: Musik-Mäzenatentum am bayrischen und am innerösterreichischen Hof, Zeitschrift des historischen Vereins für Steiermark 83 (1992), str. 242-244.

${ }^{38}$ RISM B/I $1565^{12}$ in RISM B/I $1566^{7}$.

${ }^{39}$ RISM A/I L930.

${ }^{40}$ M. Farahat, nav. delo, str. 126-137. Farahat je razpravljala o Lassovih vilanelah iz zbirke iz leta 1581, ki bi lahko bile izvedene na predstavi commedie dell'arte v Münchnu leta 1568 .

${ }^{41}$ Cosimo Bottegari, Il libro di canto e liuto $=$ The song and lute book, ur. Dinko Fabris in John Griffiths, Biblioteca musica Bononiensis IV/98, Bologna, Forni, 2006, str. 7-11.

${ }^{42}$ Horst Leuchtman, Troiano, Massimo, Grove Music Online. 
skladbe nastale v Nemčiji in da je že pred časom poklonil cesarju na Dunaju knjigo, ki jo je napisal ob poroki vojvode Wilhelma. ${ }^{43} \mathrm{Na}$ ta način je sporočil, da je vsebina knjige skladna s cesarjevimi pričakovanji. Tako kot italijansko komično gledališče so torej tudi zabavno neapeljsko vilanelo še pred iztekom desetletja sprejeli na avstrijskem dunajskem dvoru, prav tako pa tudi na graškem. Za zadnjo trditev poleg Gorzanisovih posvetil iz tiskov, ki ju je v dveh zaporednih letih naslovil najprej na sina vzpenjajočega se dvornega svetnika, mladega Jurija Khisla, nato pa na samega notranjeavstrijskega vladarja, posredno govori tudi Gorzanisova verjetna navzočnost v Gradcu leta 1573, ko naj bi igral elitni dvorni druščini. ${ }^{44}$

Prepevanje neapeljskih vilanel si v krogu »italofilnih« avstrijskih plemičev zamišljamo kot improvizacijo komičnih scenarijev, ki so najverjetneje nastajali sproti in na hitro, zajemali gradivo iz različnih virov in vključevali različne na hitro sestavljene prizore. ${ }^{45}$ Razen opisa prizora serenadnega prepevanja pod kurtizaninim oknom, ki se je ohranil v Troianovem opisu, v besedilnih virih niso jasno zabeleženi. Pa vendar jih lahko prepoznamo v številnih slikovnih virih, kot na primer v lesoreznih naslovnih ilustracijah drobnih knjižnih zbirk besedil priljubljenih pesmi brez notnih zapisov, ki so jih v Italiji redno izdajali po letu $1550 .{ }^{46}$ Poleg pogosto uporabljene ilustracije z naslovnice zbirke neapeljskih vilanel brez glasbenega zapisa iz časa ok. 1550, ki prikazuje serenadno prepevanje plemičev pod oknom kurtizane, prepoznamo kot take tudi nekatere druge ilustracije naslovnic pesemskih zbirk s komično vsebino, na primer upodobitev plemiča pod oknom dekleta, ki jo nadzoruje »staruha«, ali dvorjenje s pesmijo na plemiškem vrtu. ${ }^{47}$

Neapeljsko vilanelo Gorzanisovega časa bi lahko okarakterizirali tudi kot neke vrste hibridno glasbeno zvrst, ki v sebi združuje tako prvine burleskne poezije kot commedie dell'arte. Prisvojila si je parodični način izražanja in evfemistični besednjak prve ter tipizacijo likov in komično teatralno podajanje besedila druge. S tega zornega kota jo lahko uvrstimo v širši kontekst poistovetenja z italijansko komično kulturo, ki se je po letu 1568 utrdila na dunajskem in graškem habsburškem dvoru ter med deželnim plemstvom.

${ }^{43}$ Massimo Troiano, Il quarto libro delle sue rime et canzoni alla napolitana a tre voci, Benetke, Girolamo Scotto, 1569, str. 2.

${ }^{44}$ Berndt Baader, Der bayerische Renaissancehof Herzog Wilhelms V. (1568-1579): ein Beitrag zur bayerischen und deutschen Kulturgeschichte des 16. Jhdts., Leipzig in Strasbourg, Heitz \& co., 1943, str. 233. Vojvoda Wilhelm V. je namreč ob obisku svoje sestre leta 1573 prisluhnil igranju slepega lutnjista.

${ }^{45}$ Richard Andrews, Scripts and scenarios: The performance of comedy in Renaissance Italy, Cambridge, Cambridge University Press, 1993, str. 195-199.

${ }^{46}$ Bianca Maria Galanti, Le villanelle alla napolitana, Firence, Olschki, 1954.

${ }^{47}$ Villanesche alla napolitana et villotte bellissime, con altre canzoni da cantare, Benetke [?] ok. 1550, naslovnica; Nuova scielta di vilanelle et altre canzoni ingeniose et belle et una barceletta in dialogo bellissima, con un dialogo del Patron et del Zane, et una canzone bellissima in lingua venetiana, ok. 1550, naslovnica; Vilanesche opera bella et dilettevole, dove si contiene varie vilanesche napolitane, et un capitolo di uno, qual fu costante alla sua inamorata, Benetke 1585, naslovnica; Bibliografia delle stampe popolari Italiane della R. Biblioteca nazionale di S. Marco di Venezia 1, Bergamo 1913, str. 240, 259. 


\section{Notni primer 1: G. Gorzanis, L'altro giorno mi disse}
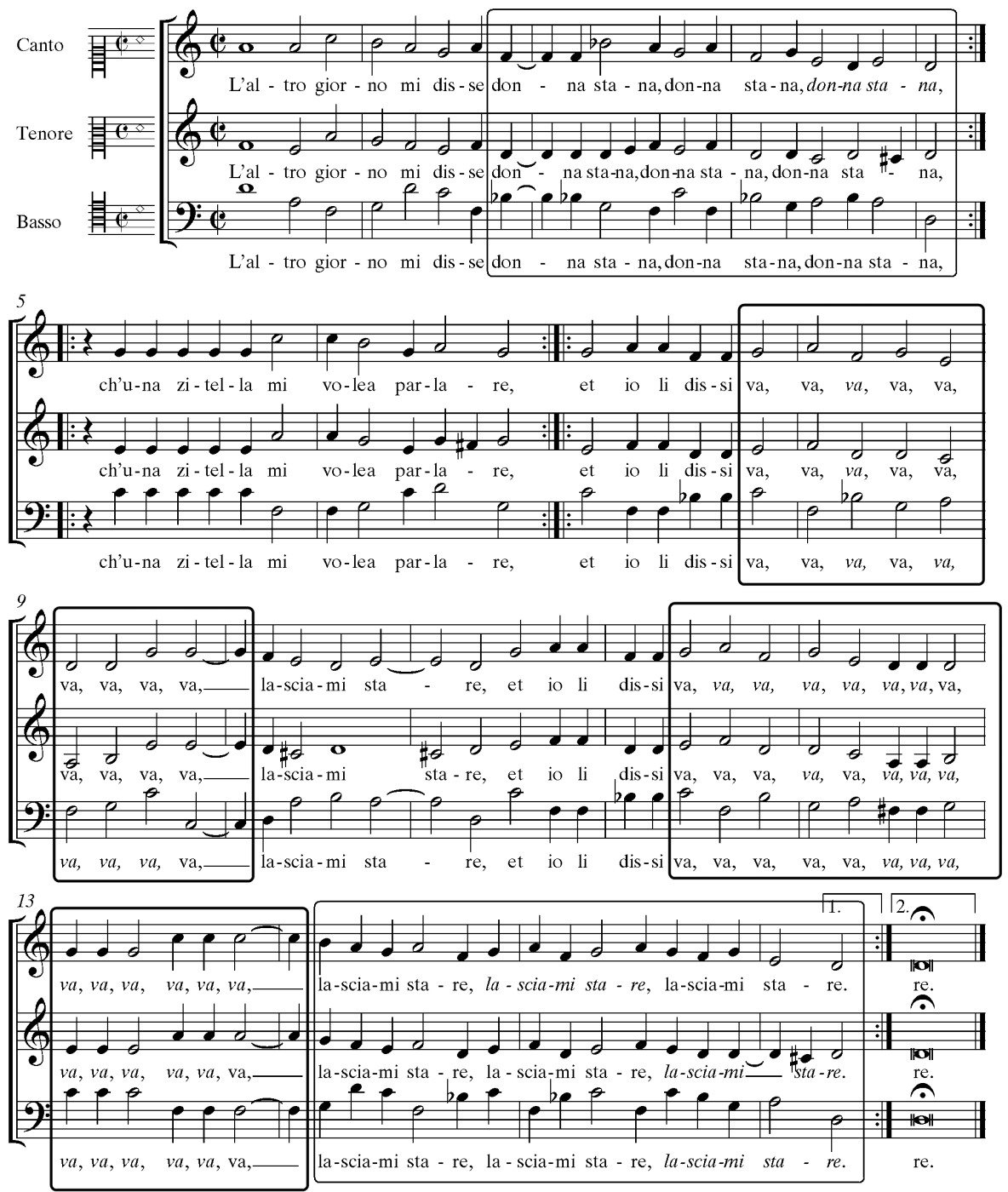

2. Con le tue ciancie sono inviluppato, si che non credo niente al tuo parlare, però te dico va, lasciami stare.
3. Più di tre volte berteggiato m'hai, e col mio danno m'hai fatt'imparare, però te dico va, lasciami stare.
4. Tutte 'ste vecchie sono ladroncelle, incantatric'e forfant'e fallace, si che te dico va, lasciam'in pace. 
Notni primer 2: G. Gorzanis, Non fu mai donna
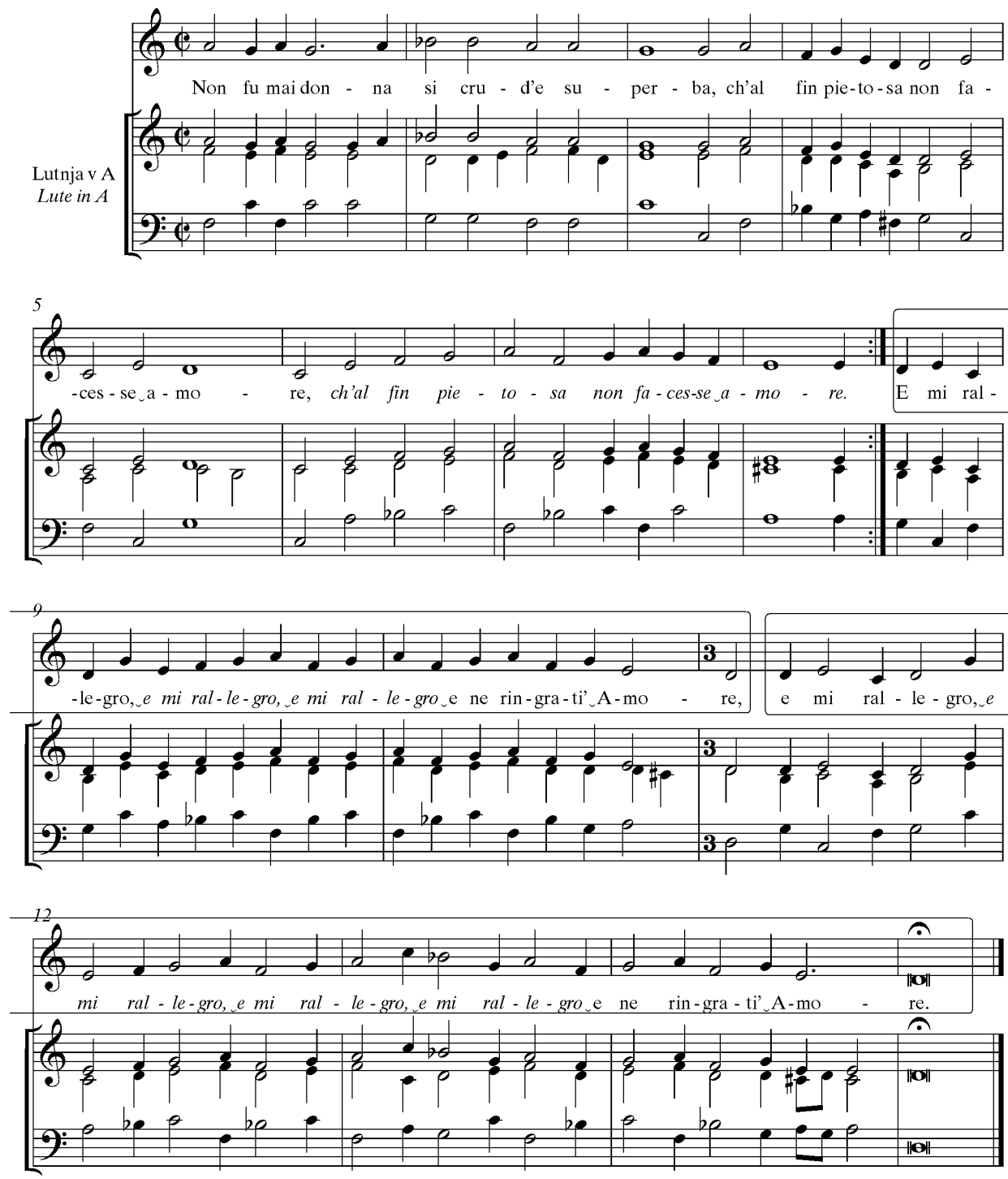
Notni primer 3: G. Gorzanis, Donna gentil non so
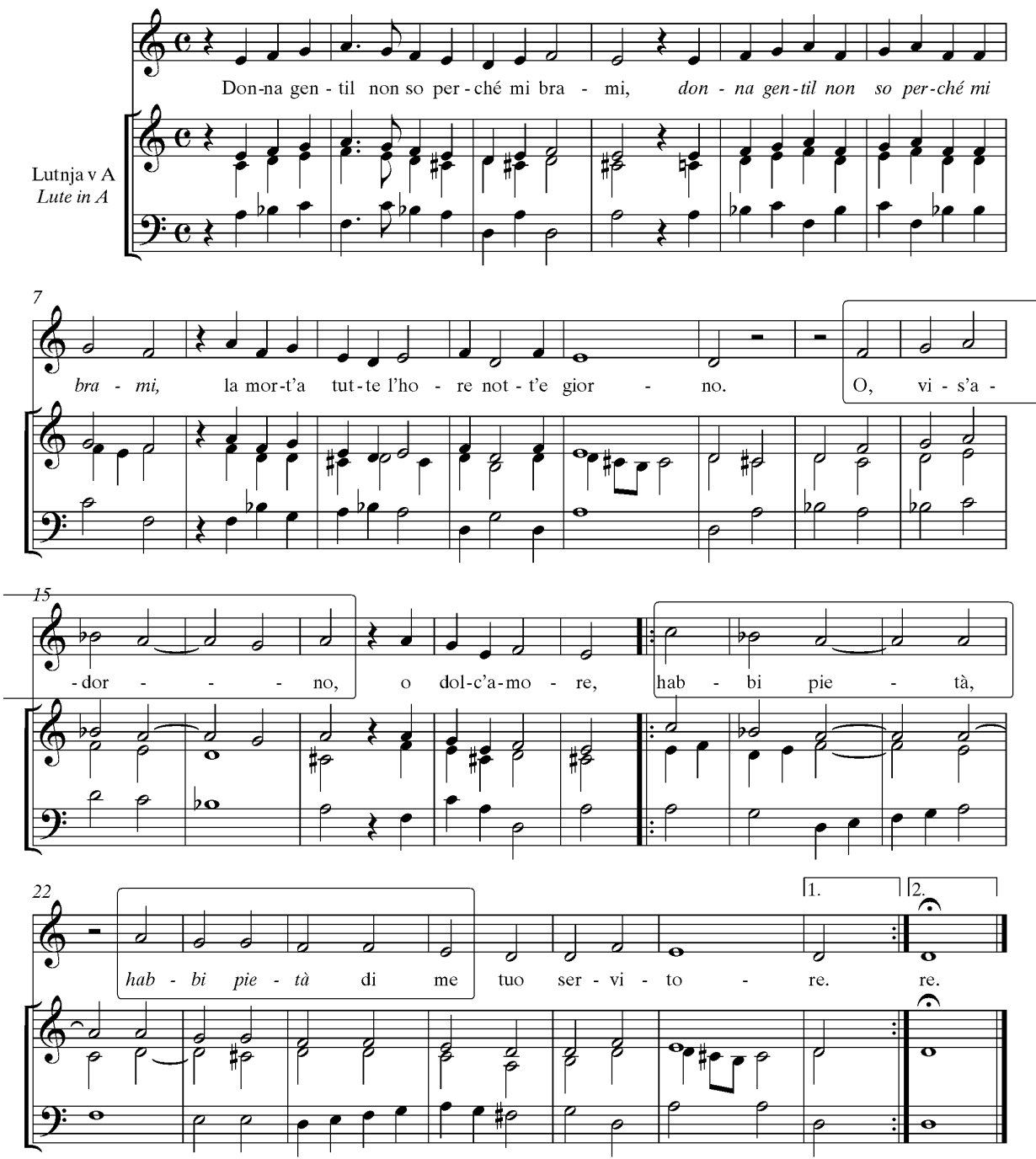
Notni primer 4: G. Gorzanis, Da che si parte il sol
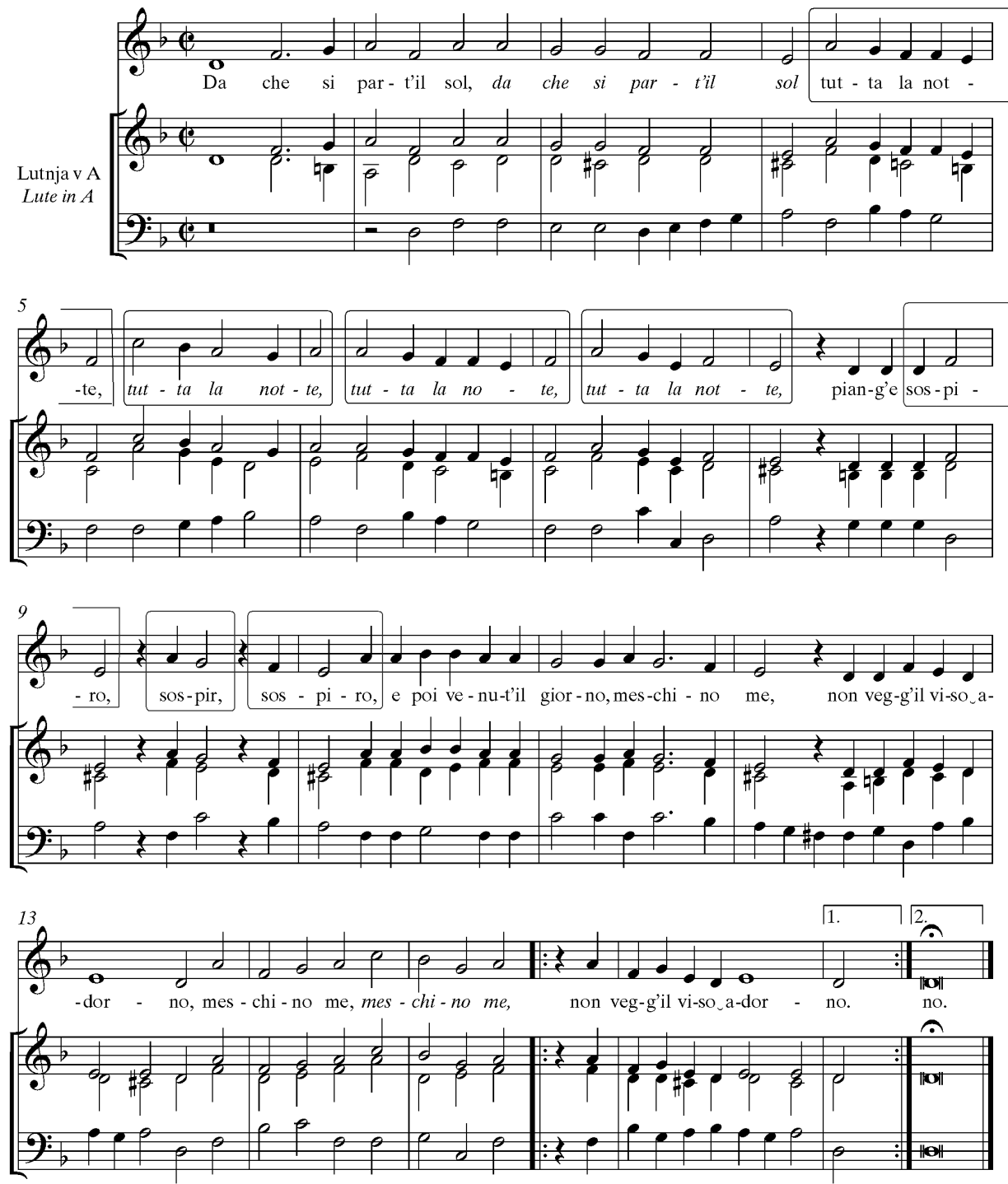

2. Si part'il sol e la notte ritorna, il solito martir che mi disface, meschino me, ch'in lei non trovo pace.
3. Dapoi ritorna 'l dì chiaro e sereno, in me 'l dolore qual mi fa morire, meschino me, non vegg'il mio desire.
4. Si che la nott'e 'l giorn'a tutte l'hore, io mi consumo, ahi lasso, a puoco a puoco, meschino me, ch'in lei non trovo luoco. 


\section{Notni primer 5: G. Gorzanis, Nessuno ti cognosce}
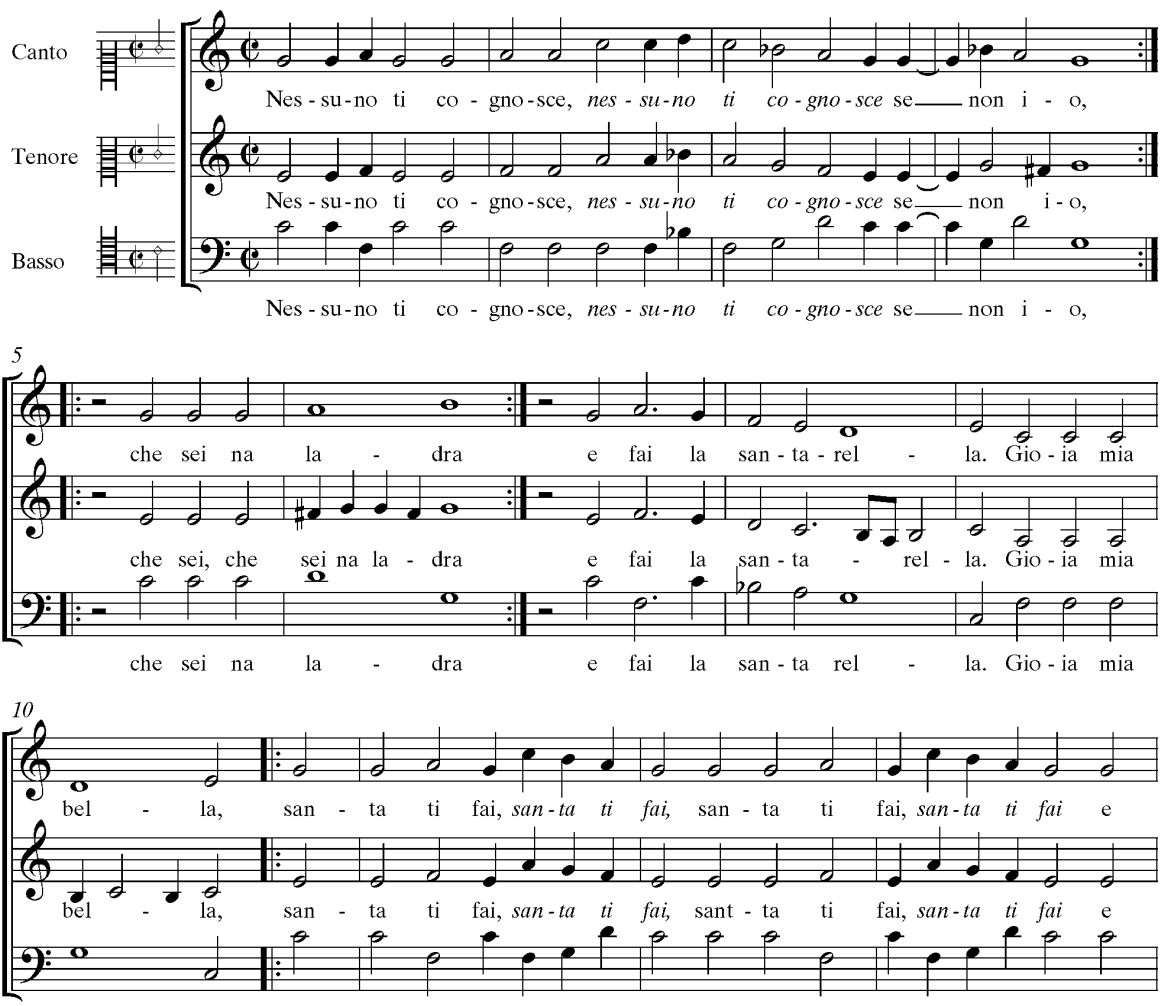

bel - la, san - ta ti fai, san-ta ti fai, san - ta ti fai, san-ta ti fai, ma

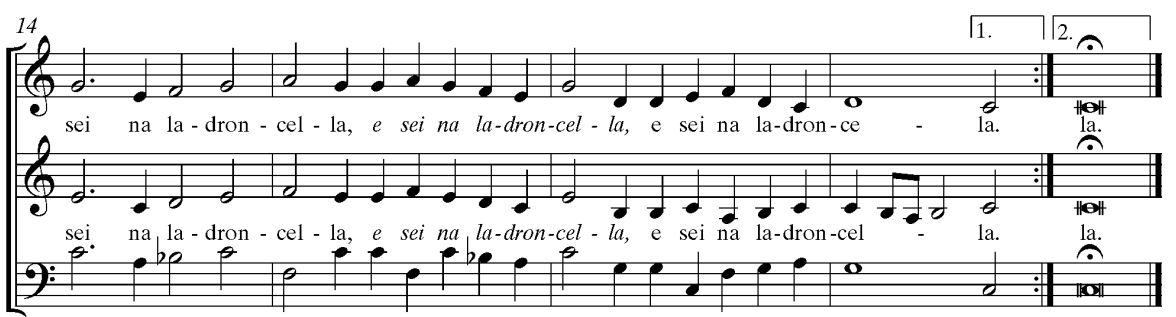

sei na la-dron - cel - la, ma sei na la-dron-cel-la, ma sei na la-dron-cel - la. la. 
Notni primer 6: G. Gorzanis, Questi capelli d'oro
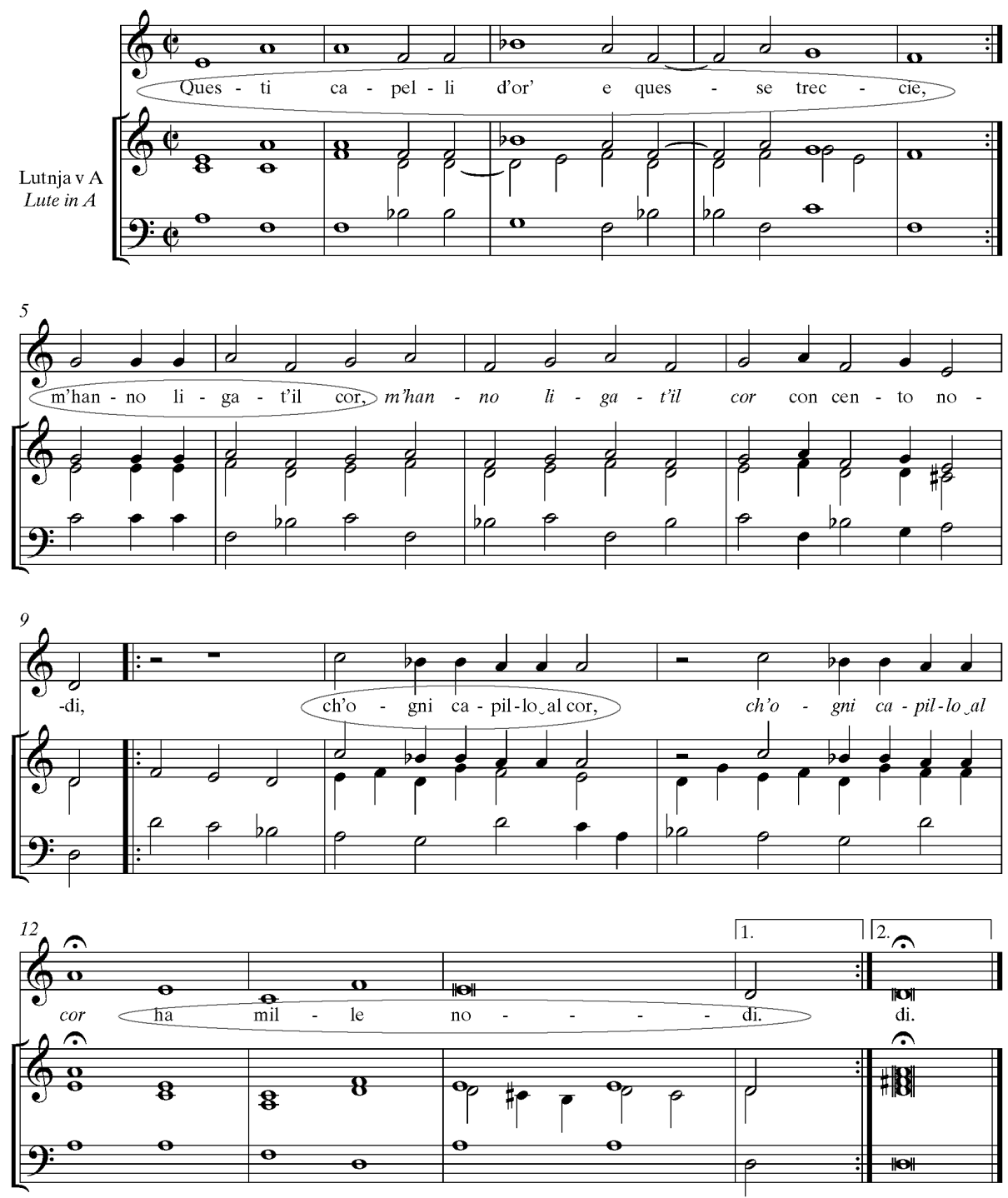
Notni primer 7: G. Gorzanis, Duca vi voglio dir
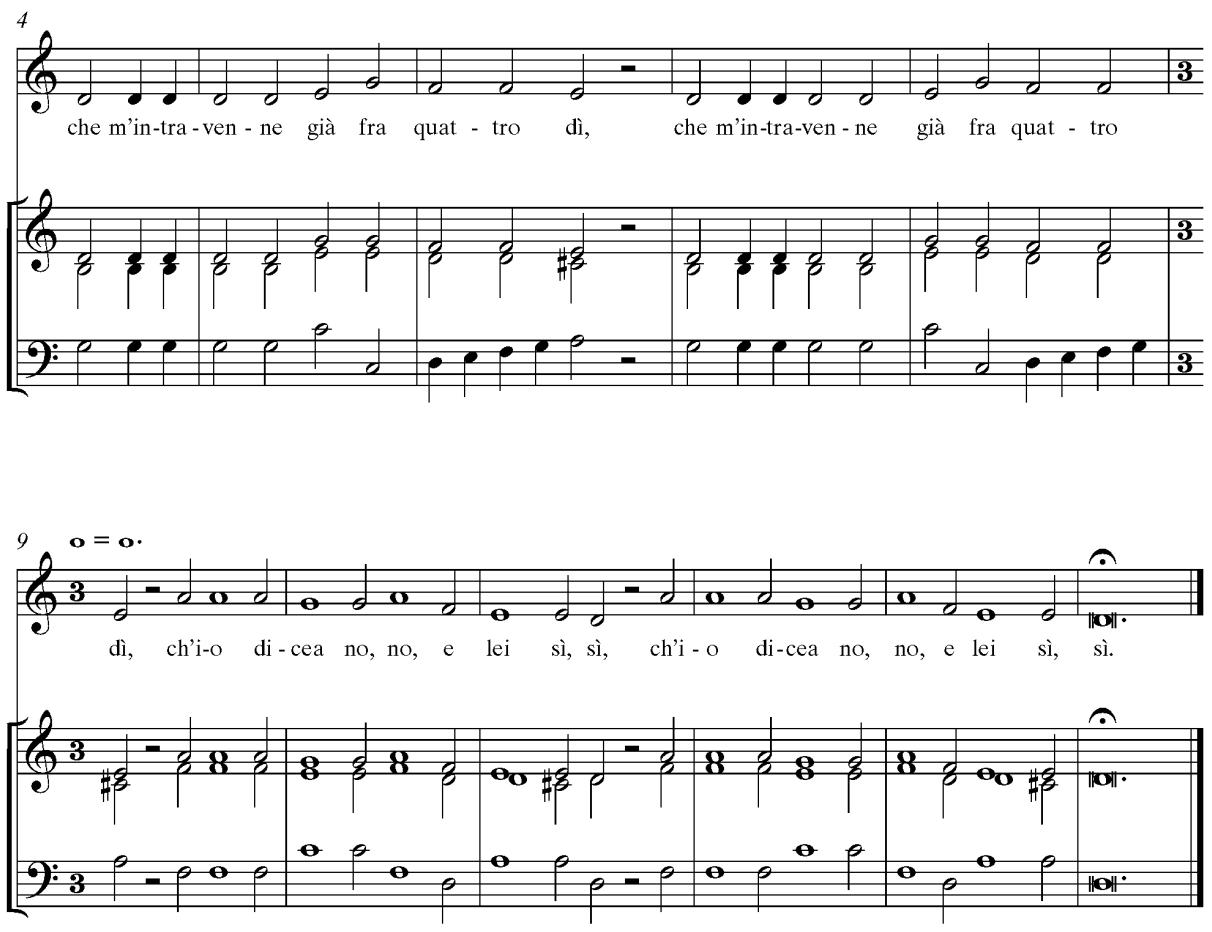
Notni primer 8: G. Gorzanis, Tu m'amasti un tempo
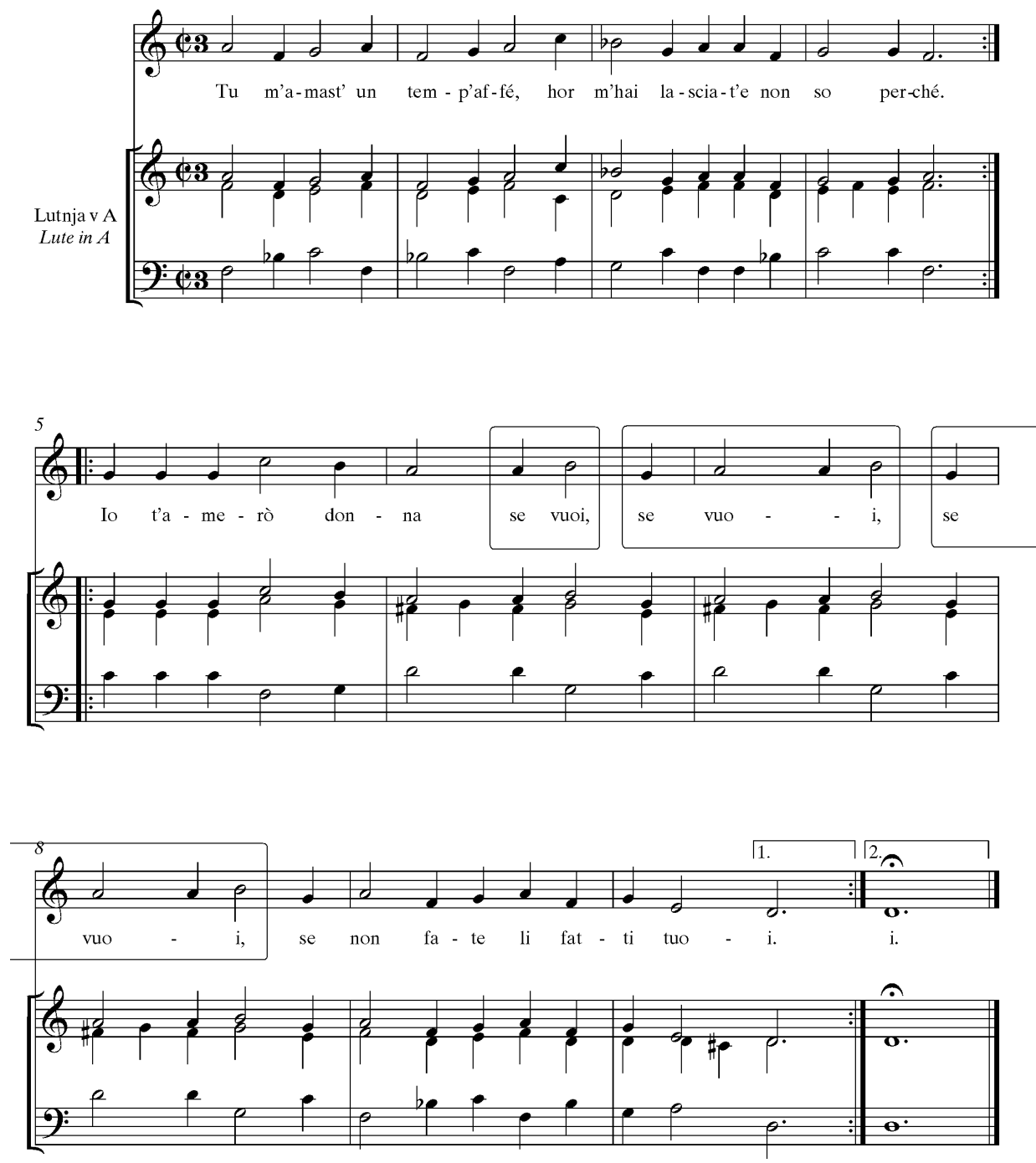


\section{VILLANELLA ALLA NAPOLITANA IN THE COMIC CULTURE OF THE AUSTRIAN LANDS AROUND 1570: THE NAPOLITANE BY GIACOMO GORZANIS}

\section{Summary}

The villanella alla napolitana or napolitana of the 1570s was a funny love song. Almost all poems in types and topics are linked to the same characteristics and situations. In the villanellas, the speaking subject addresses imaginary persons or the audience directly. In a speech, which includes personal and demonstrative pronouns, hyperbolic expressions, interrogative requests and fillers like colloquial phrases, it simulates an action, typical for theatrical performances. The songs are typically performed by male characters, their singing includes mimic and gesticulatory elements with a recognizable comic effect. These characteristics occur as the essential elements of simple Italian songs that spread, as a comic music genre, to countries beyond the Italian speaking area. Arguments also illustrate the napolitane by Giacomo Gorzanis (c. 1530-after 1574), which is preserved in two Venetian prints.

A typical poetic type of Gorzanis' napolitane is the complaint of a frustrated male speaker, whose emotional distress is caused by a relationship with an unstable woman. The lover suspects that his beloved is cheating on him or he realizes that the love relationship has ended. In the subsequent strophes his bitter complaint and accusing statements escalate into a parody. The listener is a calculating lady who does not keep to her promises of lovemaking. A large number of napolitane by Gorzanis belong to the category of serenades. In some cases the elated suitors profess their love to a young chosen beloved by a description of her image or an imaginary meeting. In other songs, the tortured suitor describes his pathetic state using comical colloquial phrases and Petrarchan paradoxes, and pleads for help from his lover.

In the tunes by Gorzanis we can recognize certain stereotypical figures of older Neapolitan composers of villanellas, such as sudden quickening or slowing down of the tempo or sudden stops, change in metrum, and diversity of rhythmic emphases, as well as funny shortenings and excessive repetitions of individual words. In the context of a short poetic stanza, these figures are often out of proportion and appear to perform the role of ironic messages of sentimental content. Although the lyrics are read as the complaint of a scorned lover, the composition changes it into a mockery. Gorzanis added to these per se communicative lyrics a pallet of cues for comic interpretation. Apart from the caricature-like presentation of certain words or phrases, he provided opportunities for improvised mimic and gesticulation, which contribute towards the sum of mocking, fun and humorous moments.

Connecting subtle clues from Gorzanis' villanellas and historical facts proves that the Austrian nobility attempt to identify themselves with the Italian comic culture.

The role and importance of the villanella alla napolitana as one of the leading vocal and instrumental musical forms of social life, as it took place at the Italian courts, within the framework of humanistic academies and bourgeois salons, changed in time, place and context. However, it still maintained an apparent simplicity of musical and literary style, and above all a funny character, which hides by presenting love confessions of scorned, rejected or desirable men to a fictitious female listener. 